\title{
The Differences in Experiences Among Multi-Level Healthcare Leaders, Between the First and the Second Wave of the COVID-I 9 Pandemic: Two Cross-Sectional Studies Compared
}

\author{
Bibi Hølge-Hazelton (D) ${ }^{1,2}$ \\ Line Zacho Borre (D) \\ Mette Kjerholt $\mathbb{D}^{3}$ \\ Brendan McCormack (D) 1,2,4 \\ Elizabeth Rosted (iD ${ }^{2,5}$ \\ 'Zealand University Hospital, Research \\ Support Unit, Zealand University Hospital, \\ Roskilde, Denmark; ${ }^{2}$ University of Southern \\ Denmark, Department of Regional Health \\ Research, University of Southern Denmark, \\ Odense C, Denmark; ${ }^{3}$ Department of \\ Hematology, Zealand University Hospital, \\ Roskilde, Denmark; ${ }^{4}$ Centre for Person- \\ Centred Practice Research, Queen \\ Margaret University Edinburgh, \\ Musselburgh, East Lothian, EH2I 6UU, UK; \\ ${ }^{5}$ Department of Oncology and Palliative \\ Care, Zealand University Hospital, Roskilde, \\ Denmark
}

Purpose: To identify the differences in experiences during wave I and II of the COVID-19 pandemic among healthcare leaders.

Background: It is expected, that working conditions for COVID-19-pandemic frontline staff will change, as health care organizations have gained experience with handling the consequences of the disease.

Methods: An online survey was sent out to Danish health care leaders during the first and the second pandemic wave. Comparative analyses were performed in relation to three key characteristics: management level, management education and experiences as a leader.

Results: Eighty-nine health care leaders completed both surveys. Significant differences were found within the entire group across the key characteristics as they felt more prepared for each stage of the situation, they had more influence on the decisions taken, and they felt more concerned about the quality of treatment and care and their own health. Further significant results related to the three key characteristics were found at 1) Management level: The heads of department experienced being better informed, having more overview of their tasks and that these were meaningful. The ward managers experienced being more able to work in consistency with own beliefs and values, though they felt more overloaded. 2) Level of management education: Leaders, without a formal management education, experienced being more supported by staff. 3) Years of experiences as leader: Leaders with more than five years of experience, experienced being more prepared and informed, had more influence on decision-making, and were more worried about their own health.

Conclusion: The learning from experience that happens naturally in crisis situations is the reason why the leaders feel more prepared. However, there is a need for further leadership and practice development, to create contexts where leaders feel more ready for all aspects of their role.

Keywords: follow-up, clinical leadership, management, communication, online survey

\section{Plain Language Summary}

This study is comparing two surveys sent to health care leaders during the first and the second wave of the COVID-19 pandemic in Denmark. In all, 89 health care leaders completed both surveys, and the development across the two waves is reported within the characteristics: Management level, formal management education, and years of experience as a leader. Results revealed, that amongst others, the leaders felt more prepared for the second wave of the pandemic and had more influence on the decisions taken. At the same time, they felt more worried about their own health during the second wave. It is clear, that
Correspondence: Bibi Hølge-Hazelton Zealand University Hospital, Research Support Unit, Zealand University

Hospital, Roskilde, Denmark

Tel +4527I24286

Email bibh@regionsjaelland.dk 
preparedness for crisis is a key consideration and one that requires strategic leaders to consider practice development. In addition, there is a need for further leadership development to create contexts where leaders feel more ready for all aspects of their role.

\section{Introduction}

In a crisis situation like the COVID-19 pandemic, it is the duty of leaders to provide their staff with clear information about what lies ahead of them, while, at the same time, reinforcing the importance of staff effectiveness and the organization's commitment to supporting the enablement of effectiveness. ${ }^{1}$

However, the COVID-19 pandemic has created a situation, few health care leaders were able to imagine just a few years ago. ${ }^{2}$ In a cross sectorial study at a Danish hospital among 115 health care leaders during the first COVID-19 wave in 2020, some leaders experienced a lack of timely relevant information, involvement in decision-making, and acknowledgement, resulting in the leaders sense of own competences and leadership being pressured, when they had to balance different stakeholders' needs. ${ }^{1}$ In order to support practice development, including authentically engagement and transformation of leadership practices, the researchers behind the study presented these results to the executive management and the leaders' networks at the hospital., ${ }^{3,4}$ This quickly led to a researcher facilitated workshop between ward managers and the executive management and to a new communication strategy. This resulted in agreements on a more constructive and sustainable way forward, including strengthening communication and providing direct leadership support. When the second COVID-19 wave began late in 2020, the researchers repeated the study.

\section{Purpose}

The aim of this study was to identify and discuss the differences in experiences during the first and second wave of the COVID-19 pandemic, spring 2020 and winter 2020/2021 respectively, among healthcare leaders.

\section{Methods}

\section{Design}

The study was a cross sectional descriptive and comparative study, using questionnaires. ${ }^{5}$ It was based on the principles of applied research. ${ }^{6}$ An on-line survey was developed for this study, as no validated questionnaire appropriate for our purposes was available. An
EQUATOR-checklist for cross-sectional studies (STROBE checklist) was applied. ${ }^{7}$

\section{Sample and Setting}

The study took place at a regional acute hospital complex in Denmark. The hospital has departments at four different locations and has in total 738 beds and 19 clinical departments, including medicine, surgery, and intensive care.

All clinical and para clinical leaders with staff responsibility were invited to complete the survey. This included physiotherapists, doctors, nurses, biomedical laboratory technicians, medical secretaries, radiographers, midwives, and dentists. Leaders were defined as employees from clinical and para clinical departments with staff responsibility. They were recruited through data supplied by the Human Resources Department, who identified the population by focusing on job title and responsibility.

Para clinical departments are those, who provide a service for patients without direct involvement in care. Even though these leaders did not have direct responsibility for patient care, they were included in the study, as they represented an important part of the complete COVID-19 organization.

\section{Development of the Survey}

As no tool to examine health care leaders' experiences during the COVID-19 pandemic was recommended by national leading management researchers, an extensive literature review was conducted. Based on the findings from the literature review, an expert group developed a questionnaire with 27 questions. The expert group consisted of two nursing professors, a clinical nurse research leader, a postdoc nurse, and a $\mathrm{PhD}$ nurse specialist. The questionnaire was face and content validated. A detailed description of the development, and testing of the survey instrument, can be found in a previous publication. ${ }^{8}$

The survey used during the second wave, was similar to the one distributed in the first wave except for a few alternations, described below. It was decided to make as few changes as possible, in order to increase the reliability and comparability of the results from the two surveys.

\section{Survey Structure}

The survey consisted of questions concerning the participants' professional background, management level, years of experience as a leader, management education, and whether the participant had management responsibility for staff.

The subsequent 27 questions focused on the leaders' own experiences during the first six weeks of COVID-19, 
in the first and the second wave, respectively (Survey I and Survey II).

Responses were placed on a five-point Likert-scale (Always, Often, Sometimes, Seldom, Never/Almost never). In addition, the participants had the opportunity to expand on their responses in a column for open-ended answers for every 5th question. Finally, the participants were asked to evaluate, whether the handling of COVID19 had helped them to develop as leaders.

\section{Changes to Survey II}

Added Questions in Survey 2

Two questions, regarding the participants own story of infection with COVID-19, and whether the participant had a COVID-19 vaccination, were added to the questionnaire.

\section{Changing the Order of the Questions}

In Survey II, the four questions, with patient-related wording, were placed together in the middle of the questionnaire instead of being spread out in the questionnaire. In this cluster, an additional answering option "Not relevant" was added. ${ }^{9}$

\section{Data Collection}

The survey was distributed via the online program SurveyXact ${ }^{\circledR}$ with a specific hyperlink. It is a secure data management application. ${ }^{10}$ Survey I was distributed on 24 April 2020, and Survey II 28 January 2021. In both rounds, reminders were sent at weekly follow-ups with the survey being closed three weeks after it was first distributed. Completing the questionnaire was voluntary.

\section{Data Analysis}

The survey data were analysed with descriptive statistics using IBM SPSS version 23.0 (IBM Corp., Armonk, NY, USA). Only fully completed questionnaires were included in the analyses.

Participants' characteristics are presented as numbers and means. Data were investigated for normal distribution using the Shapiro-Wilk test. ${ }^{11}$ Chi-Square test was used to investigate the goodness of fit between results of the two surveys. ${ }^{11}$

As all data were non-normal distributed, a Wilcoxon Signed Rank test was used as it compares longitudinal data from the same participants collected at different times. For this test, it is a prerequisite that: 1) the dependent variable must be measured at the ordinal level (Likert scale), 2) the independent variables are related and categorical, and 3) the distribution of differences between the scores of the groups are symmetrically shaped. ${ }^{11}$ This test only includes the participants that answered both questionnaire I and II.

Results are presented with a $P$-value $(<0.05$ was considered significant for all analyses), negative ranks (number of participants who scored lower in the second, than in the first questionnaire), positive ranks (number of participants who scored higher in the second, than in the first questionnaire), and ties (number of participants who score the same in both surveys).

\section{Grouping of Data}

Several analyses were performed, and results were reviewed for relevance to the purpose of this study. Groupings that showed significant differences in experiences of the participants were selected, and results analysed and discussed. The three relevant groupings were:

- Management level: Head of department or ward manager.

- Formal management education: Yes or no.

- Years of experience as leader: Less than two years vs more than five years.

\section{Results}

Responses from participants completing a survey at only one point are not included in this analysis. The number of participants who completed one of the surveys, but not the other, is presented in Table 1.

\section{Participant Characteristics}

Table 1 shows demographic data for those 89 leaders who completed both Survey I and Survey II.

\section{Comparative Analyses}

Results are presented as a table for the entire group of leaders. Results, with significant differences in the subgroups are presented as histograms and with calculated percentages for ranks and ties. Extended tables with results can be found in Appendix 1 Tables 1-6.

\section{All Leaders}

Results comparing answers from the entire group of leaders answering both surveys are presented in Table 2 . Comparing the difference in answers from the entire group revealed a statistical difference between the surveys for Q6 $(P=0.01)$, where more participants $(n=40)$, more 
Table I Demographic Data for Leaders Completing Both Surveys

\begin{tabular}{|c|c|c|c|c|}
\hline & \multicolumn{2}{|c|}{ Survey I } & \multicolumn{2}{|c|}{ Survey II } \\
\hline & \multicolumn{2}{|c|}{ Completed $(n=89)$} & \multicolumn{2}{|c|}{ Completed $(n=89)$} \\
\hline Completers not represented in the other survey and thus not included & \multicolumn{2}{|c|}{$n=26$} & \multicolumn{2}{|c|}{$n=41$} \\
\hline Characteristics & $\mathrm{n}(\%)$ & Mean (Range) & $\mathrm{n}(\%)$ & Mean (Range) \\
\hline \multicolumn{5}{|l|}{ Gender $^{\mathrm{a}}$} \\
\hline Male & $17(19)$ & & $17(19)$ & \\
\hline Female & $72(81)$ & & $72(8 I)$ & \\
\hline Age (years) & & $53(39-66)$ & & $54(39-67)$ \\
\hline \multicolumn{5}{|l|}{ Profession } \\
\hline Nurses & $45(51)$ & & $45(51)$ & \\
\hline Doctors & $16(18)$ & & $16(18)$ & \\
\hline Physiotherapists & $4(5)$ & & $4(5)$ & \\
\hline Midwife & $I(I)$ & & $I(I)$ & \\
\hline Medical secretaries & $10(11)$ & & $10(11)$ & \\
\hline Radiographers & $2(2)$ & & $2(2)$ & \\
\hline Biomedical laboratory technicians & $11(12)$ & & $11(12)$ & \\
\hline Dentist & $0(0)$ & & $0(0)$ & \\
\hline Physicist & $0(0)$ & & $0(0)$ & \\
\hline \multicolumn{5}{|l|}{ Type of department } \\
\hline Clinical & $72(8 I)$ & & $72(81)$ & \\
\hline Para clinical & $17(19)$ & & $17(19)$ & \\
\hline \multicolumn{5}{|l|}{ Management level } \\
\hline Head of department & $30(34)$ & & $31(35)$ & \\
\hline Ward manager & $59(66)$ & & $58(65)$ & \\
\hline \multicolumn{5}{|l|}{ Formal management education ${ }^{a}$} \\
\hline Yes & $61(69)$ & & $59(66)$ & \\
\hline No & $28(32)$ & & $30(34)$ & \\
\hline \multicolumn{5}{|l|}{ Years of experience as a leader ${ }^{a}$} \\
\hline$<2$ years & $18(20)$ & & $10(11)$ & \\
\hline $3-5$ years & $14(16)$ & & $16(18)$ & \\
\hline$>5$ years & $57(64)$ & & $63(7 \mathrm{I})$ & \\
\hline \multicolumn{5}{|l|}{ Have you been vaccinated? ${ }^{\mathrm{a}, \mathrm{b}}$} \\
\hline Yes, Ist round & - & & $10(11)$ & \\
\hline Yes, both rounds & - & & $77(86)$ & \\
\hline No, not yet & - & & $2(2)$ & \\
\hline No, and I will not & - & & $0(0)$ & \\
\hline \multicolumn{5}{|l|}{ Have you been infected with COVID-19?a, b } \\
\hline Yes & - & & $11(12)$ & \\
\hline No (as far as I know) & - & & $78(88)$ & \\
\hline
\end{tabular}

Notes: 'Information based on participants' information; ' Only asked in Survey II.

often, felt prepared for the next stage of the COVID-19 situation in Survey II.

A significant difference was also found in Q8 $(P=0.00)$, where more felt that they had influence in the decisions taken during the COVID-19 situation in Survey II.
In $\mathrm{Q} 15$, the significant difference $(P=0.04)$ reveals that leaders were more concerned about the quality of treatment and care for the patients in Survey II.

Finally, a significant difference was found in Q20 $(P=0.00)$, where 35 participants, an increase of $39 \%$, 
Table 2 Comparing All Leaders' Answers from Survey I and Survey II

\begin{tabular}{|c|c|c|c|c|c|c|c|c|}
\hline No & Question & $\mathbf{N}^{\mathbf{a}}$ & $\mathbf{n}$ & $\begin{array}{l}\text { Negative } \\
\text { Ranks }\end{array}$ & $\mathbf{n}$ & $\begin{array}{l}\text { Positive } \\
\text { Ranks }\end{array}$ & $\begin{array}{l}\text { Ties, } \\
\mathbf{n}\end{array}$ & $\mathbf{P}$ \\
\hline I & $\begin{array}{l}\text { I felt able to communicate quickly, clearly and transparently to my employees } \\
\text { and collaborators }\end{array}$ & 89 & 20 & 21.90 & 19 & 18.00 & 50 & 0.47 \\
\hline 2 & I was able to work in a way that was consistent with my beliefs and values & 89 & 29 & 24.90 & 18 & 22.56 & 42 & 0.07 \\
\hline 3 & $\begin{array}{l}\text { I have taken on management duties and responsibilities that I did not have } \\
\text { before COVID- } 19\end{array}$ & 89 & 29 & 30.90 & 26 & 24.77 & 34 & 0.27 \\
\hline 4 & I had overview of the tasks my nearest leader assigned to me & 89 & 25 & 21.26 & 19 & 24.13 & 45 & 0.64 \\
\hline 5 & $\begin{array}{l}\text { I knew where to find factual knowledge of symptoms stage of the COVID-I9 } \\
\text { situation as it developed and disease }\end{array}$ & 89 & 19 & 21.16 & 21 & 19.90 & 49 & 0.91 \\
\hline 6 & I was prepared for each stage of the COVID-19 situation as it developed & 89 & 40 & 33.46 & 22 & 27.93 & 27 & $0.01 *$ \\
\hline 7 & I had meaningful tasks during the COVID-19 situation & 89 & 16 & 21.78 & 21 & 16.88 & 52 & 0.96 \\
\hline 8 & I had influence on the decisions taken during the COVID-I9 situation & 89 & 38 & 32.24 & 20 & 24.30 & 31 & $0.00 *$ \\
\hline 9 & I took complex decisions during the COVID-19 situation & 89 & 30 & 25.20 & 18 & 23.33 & 41 & 0.08 \\
\hline 10 & I had to assign staff to other tasks than they are employed to do & 89 & 30 & 31.65 & 33 & 32.32 & 26 & 0.68 \\
\hline 11 & I had to move/lend out staff to other units/departments & 89 & 17 & 22.09 & 28 & 23.55 & 44 & 0.10 \\
\hline 12 & I had the necessary resources to effectively care for patients and staff & 84 & 20 & 23.80 & 26 & 23.27 & 38 & 0.46 \\
\hline 13 & I was able to ensure that that the patients' needs were met & 79 & 16 & 20.69 & 21 & $|7.7|$ & 42 & 0.74 \\
\hline 14 & I was able to answer patients' questions about COVID-I9 & 62 & 13 & 12.77 & 10 & 11.00 & 39 & 0.35 \\
\hline 15 & I was concerned about the quality of treatment and care for our patients & 76 & 19 & 24.58 & 33 & 27.61 & 24 & $0.04 *$ \\
\hline 16 & I was kept well informed by my own nearest leader & 89 & 23 & 18.28 & 13 & 18.88 & 53 & 0.14 \\
\hline 17 & I was able to answer staff questions about COVID-19 & 89 & 18 & 15.83 & 12 & 15.00 & 59 & 0.22 \\
\hline 18 & I felt overloaded & 89 & 29 & 27.88 & 23 & 24.76 & 37 & 0.24 \\
\hline 19 & I was concerned about the health and well-being of the staff & 89 & 29 & 29.83 & 28 & 28.14 & 32 & 0.74 \\
\hline 20 & I was worried about my own health & 89 & 35 & 26.40 & 14 & 21.50 & 40 & $0.00 *$ \\
\hline 21 & I was worried about my family's health & 89 & 28 & 25.07 & 19 & 22.42 & 42 & 0.12 \\
\hline 22 & $\begin{array}{l}\text { I had the managerial competences I needed to effectively manage the } \\
\text { situation }\end{array}$ & 89 & 20 & 20.50 & 20 & 20.50 & 49 & 1.00 \\
\hline 23 & $\begin{array}{l}\text { Collaboration with the other leaders in my own department was adversely } \\
\text { affected by the COVID-19 situation }\end{array}$ & 89 & 29 & 24.38 & 20 & 25.90 & 40 & 0.33 \\
\hline 24 & $\begin{array}{l}\text { I experienced support from my leader colleagues in the rest of the } \\
\text { organization }\end{array}$ & 89 & 23 & 24.13 & 24 & 23.88 & 42 & 0.92 \\
\hline 25 & I was supported by the staff of my department/unit with the decisions I made & 89 & 16 & 21.81 & 27 & 22.11 & 46 & 0.10 \\
\hline 26 & The staff supported the decisions of the hospital management & 89 & 21 & 22.43 & 25 & 24.40 & 43 & 0.42 \\
\hline 27 & I feel well prepared if a similar situation arise again & 89 & 29 & 25.21 & 20 & 24.70 & 40 & 0.19 \\
\hline
\end{tabular}

Notes: Negative ranks (number of participants who scored lower in the second, than in the first questionnaire), positive ranks (number of participants who scored higher in the second, than in the first questionnaire), and ties (number of participants who scores the same in both questionnaires). (Items measured from I=Always; 2=Often;

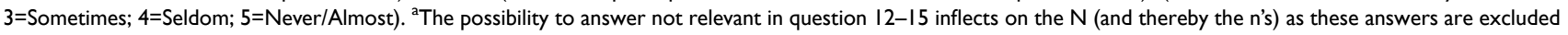
to insure equality. * $\mathrm{p}$-values are considered significant when $\leq 0.05$. 
were worried more often about their own health in Survey II as compared to Survey I.

\section{Ward Managers}

Results with significant differences for the ward managers are presented in Figure 1. To ward managers, there was a significant difference between the two surveys in Q2 $(P=0.05)$, where more ward managers more often thought that they were able to work in a way consistent with their own beliefs and values at the time of Survey II.

In Q6, a significant difference $(P=0.05)$ was found with a higher number of participants $(43.4 \%)$ who more often felt prepared for each stage of the COVID-19 situation, as it developed.

Of the 53 ward managers, nineteen $(35.8 \%)$ felt more overloaded (Q18), at the time of Survey II $(P=0.04)$ and in Q20, twenty-two (41.5\%) were more concerned about their own health $(P=0.00)$.

\section{Heads of Departments}

Significant differences for heads of departments are presented in Figure 2. To heads of departments, significant differences between Survey I and Survey II were found in Q4, where more participants (43.3\%) more often had an overview of the tasks assigned to them by their nearest leader $(P=0.03)$ at the time of Survey II compared to the time of Survey I. More participants more often felt prepared for each stage of the COVID-19 situation as it developed $(P=0.05)$, they experienced having meaningful tasks during the COVID-19 situation $(P=0.05)$, and they could influence the decisions made $(P=0.05)$ (Q6-8).

A significant difference was found between the surveys $(P=0.02)$, when more heads of departments (40\%) more often felt they were kept well informed by their own nearest leader (Q16), at the time of Survey II, compared to that of Survey I.

\section{Leaders without Management Education}

Figure 3 shows significant differences concerning leaders without a formal management education. Within this group, 50\% more often felt (Q8) that they could influence the decisions made during the COVID-19 pandemic in the second survey $(P=0.03)$.

In relation to $\mathrm{Q} 20$, more leaders without a formal management education (46.2\%) were more often worried about their own health at the time of Survey II $(P=0.02)$, and in relation to $\mathrm{Q} 25,38.5 \%$ felt to a lower degree that they were supported by the staff from their own department/unit concerning the decisions they made $(P=0.04)$.

\section{Leaders with a Management Education}

Significant results concerning leaders with a formal management education are shown in Figure 4. The leaders with

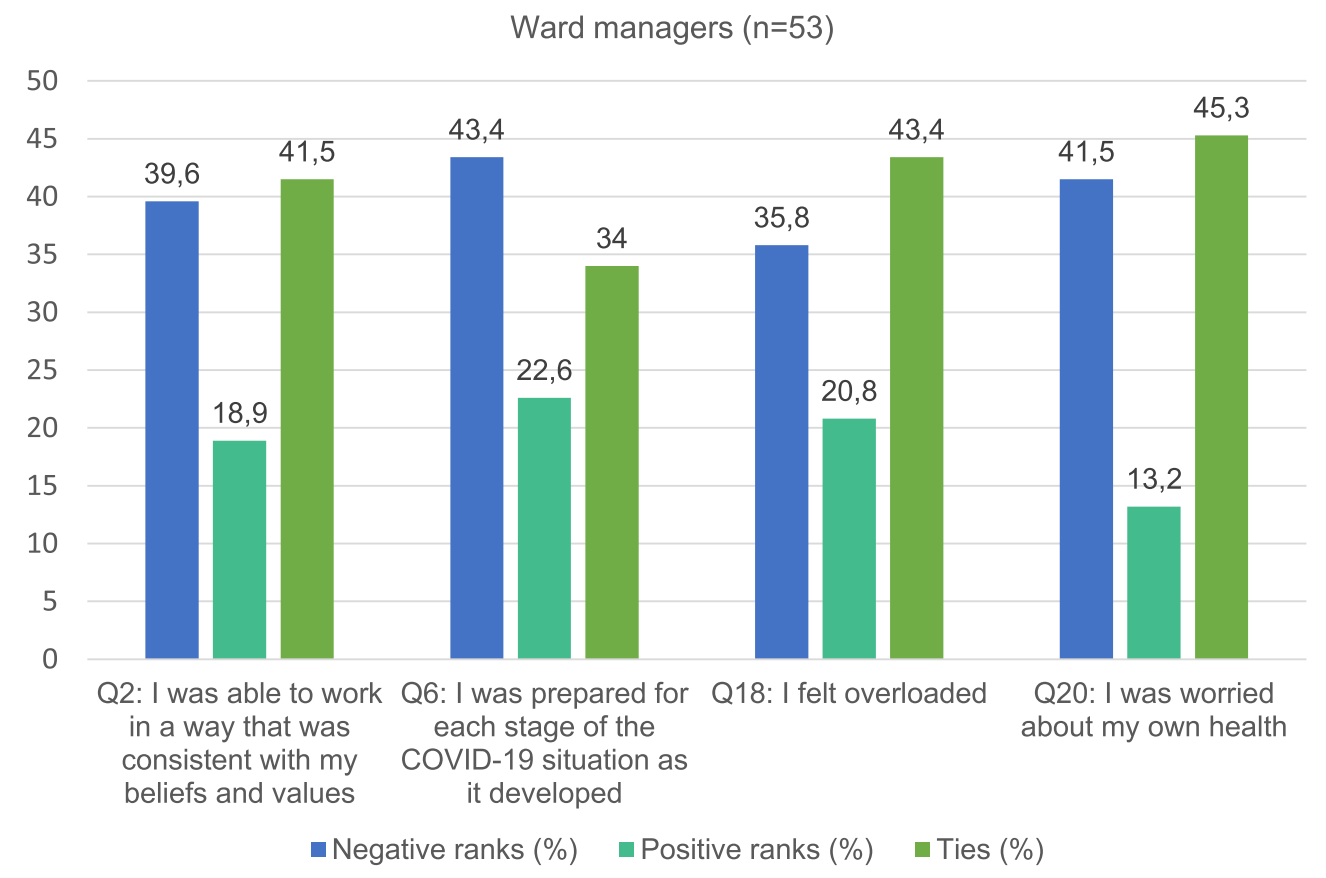

Figure I Questions with significant differences between the two surveys for ward managers. Negative ranks are percent of participants who scored lower in the second, than in the first questionnaire, positive ranks are percent of participants who scored higher in the second, than in the first questionnaire, and ties are percent of participants who scores the same in both questionnaires (Low scores represent "Always to Often" and high scores represent "Seldom to Never/Almost Never"). 


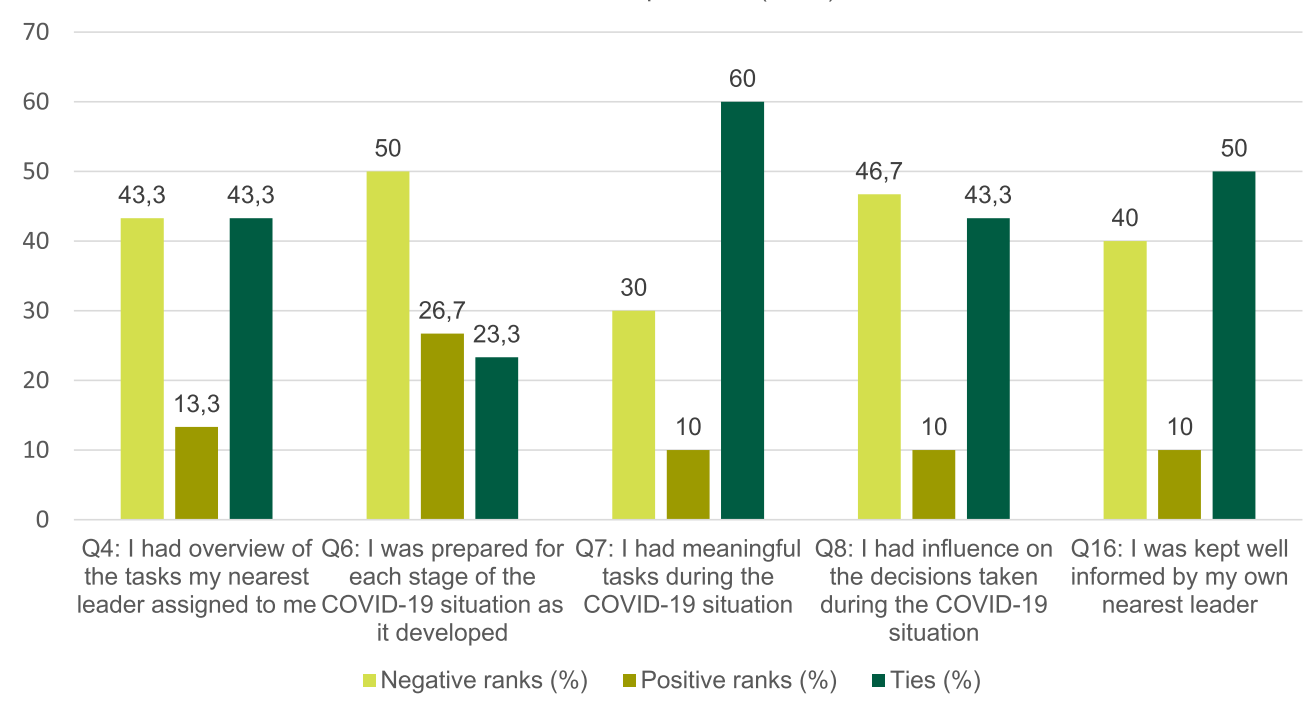

Figure 2 Questions with significant differences between the two surveys for Heads of Department. Negative ranks are percent of participants who scored lower in the second, than in the first questionnaire, positive ranks are percent of participants who scored higher in the second, than in the first questionnaire, and ties are percent of participants who scores the same in both questionnaires (Low scores represent "Always to Often" and high scores represent "Seldom to Never/Almost Never").

a formal management education showed a significant difference in their responses from Survey I to Survey II in Q6 $(P=0.03)$, where more leaders more often $(43.3 \%)$ felt prepared for each stage of the COVID-19 pandemic, as it developed over time. More leaders with a management education (41.7\%) more often felt they could influence decisions made during the COVID-19 situation $(P=0.03)$ at the time of Survey II.

However, responses to Q20 showed that 23 of the 60 (38.3\%) leaders with management education more often worried about their own health $(P=0.01)$ at the time of Survey II.

Leaders with no formal management education $(n=26)$

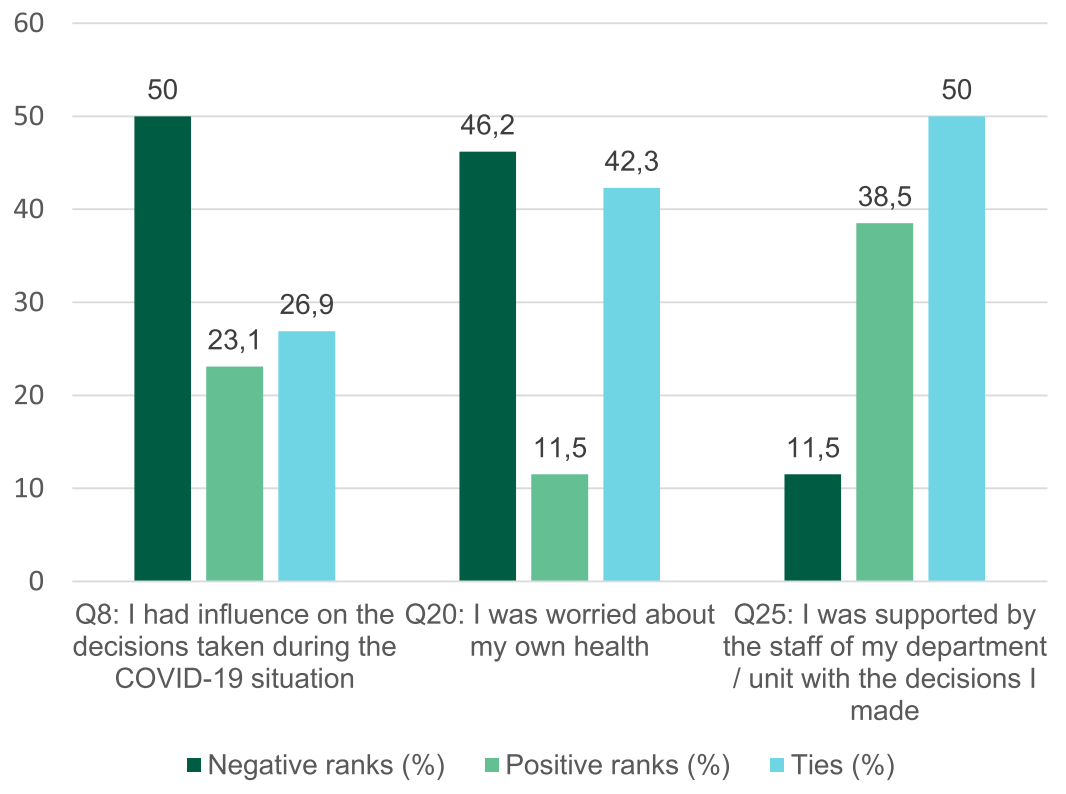

Figure 3 Questions with significant differences between the two surveys for the group of leaders with no formal management education. Negative ranks are percent of participants who scored lower in the second, than in the first questionnaire, positive ranks are percent of participants who scored higher in the second, than in the first questionnaire, and ties are percent of participants who scores the same in both questionnaires (Low scores represent "Always to Often" and high scores represent "Seldom to Never/Almost Never"). 
Leaders with formal management education $(n=60)$

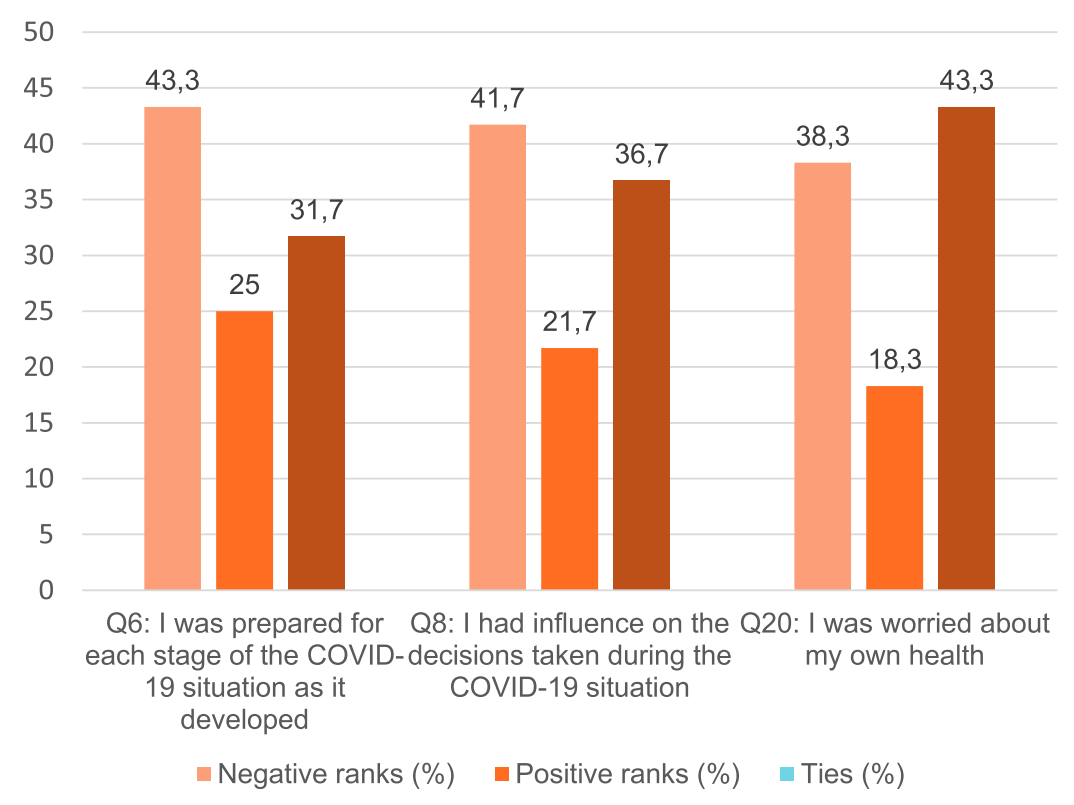

Figure 4 Questions with significant differences between the two surveys for the group of leaders with a formal management education. Negative ranks are percent of participants who scored lower in the second, than in the first questionnaire, positive ranks are percent of participants who scored higher in the second, than in the first questionnaire, and ties are percent of participants who scores the same in both questionnaires (Low scores represent "Always to Often" and high scores represent "Seldom to Never/Almost Never").

\section{Leaders by Years of Experience}

To the group of participants with 0-2 years of experience as a leader, no significant differences were found between Survey I and Survey II. Figure 5 shows the significant differences for the group with more than five years of experience as a leader.
To leaders with more than five years of experience, in Q6 more leaders more often felt prepared for each stage of the COVID-19 situation as it developed $(P=0.02)$, and in Q8, more leaders more often felt they had influence over the decisions made during the COVID-19 situation $(P=0.05)$ at the time of Survey II. Also, in Q16, more

Leaders with more than 5 years of experience as a leader $(n=57)$

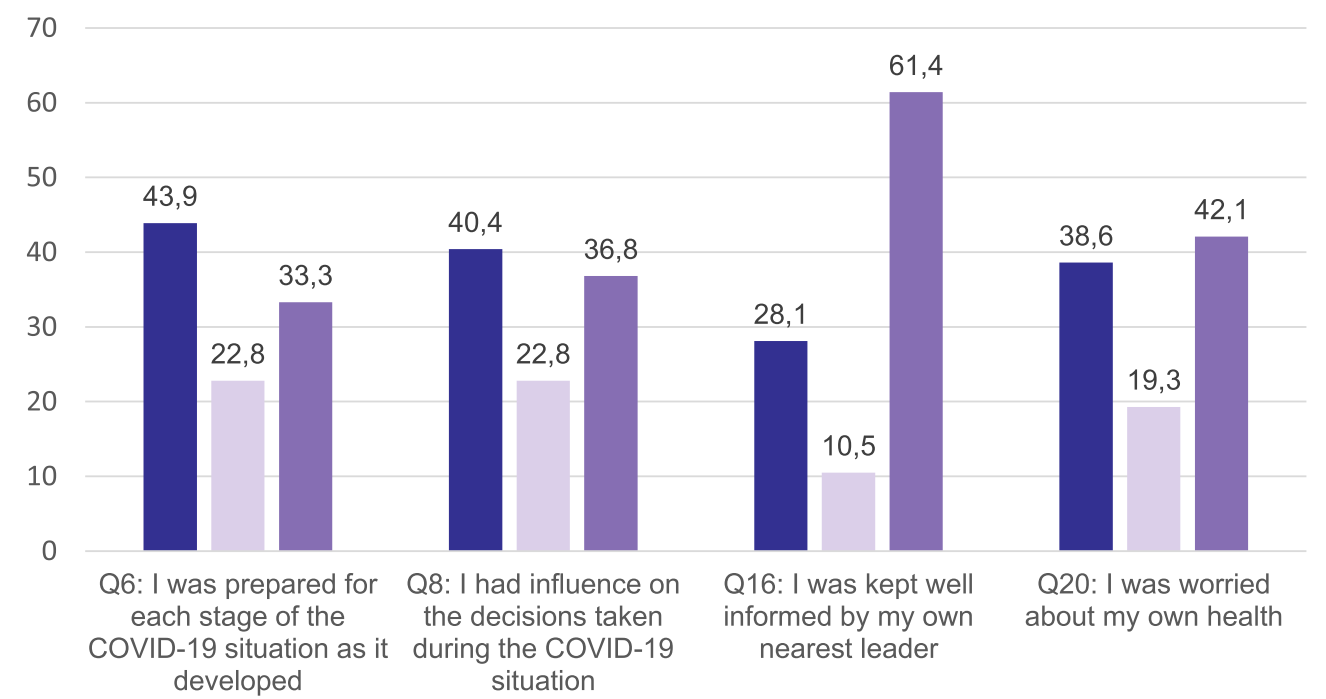

- Negative ranks (\%) - Positive ranks (\%) - Ties (\%)

Figure 5 Questions with significant differences between the two surveys for the group of leaders with more than 5 years of experience as leaders. Negative ranks are percent of participants who scored lower in the second, than in the first questionnaire, positive ranks are percent of participants who scored higher in the second, than in the first questionnaire, and ties are percent of participants who scores the same in both questionnaires (Low scores represent "Always to Often" and high scores represent "Seldom to Never/Almost Never"). 
leaders more often felt well informed by their nearest leader $(P=0.05)$ at the time of Survey II.

Additionally, in Q20, twenty-two of the 57 leaders $(38.6 \%)$ felt more worried about their own health $(P=0.04)$ at the time of Survey II.

\section{Discussion}

This study raises a number of issues that need to be investigated and discussed further. However, in order to provide useful practical knowledge for leaders during and post crises, we have narrowed the discussion to focus on the following characteristics: Management level, formal management education, and years of experience as a leader. ${ }^{8}$

The choice of analyses meant that we could only include the 89 hospital leaders who participated in both surveys. This choice has obvious consequences, because 130 leaders participated in Survey II, resulting in the experiences of 26 participants from Survey I and 41 participants from Survey II not being included in the comparative analysis.

At the time of Survey II, it is not surprising that the leaders more often experienced being prepared for the next steps of the COVID-19 situation, having more influence over decisions, and being less concerned about the care and safety of their patients. They had gained new knowledge and experiences from the first wave regarding responsiveness and resilience at different organizational levels. There may be several explanations, as to why these differences are seen. First, in Denmark, there was no sign of a major healthcare system breakdown, similar to what was seen in other countries. ${ }^{12,13}$ Secondly, the hospital management's response to the learning from the first wave, included a new communication strategy and a reorganization of the COVID-19 units. Finally, the leaders had experienced that they themselves and their staff were able to handle the situation in a safe and professional manner despite being under pressure.

The leaders also responded, more often in Survey II compared with Survey I, that they were more worried about their own health. It must be emphasized though, that in Survey I, the leaders had expressed concerns about their own health. ${ }^{8}$ Their increased worries may arise from the fact that a larger percentage of all health care leaders (12\%) had been infected with COVID-19, compared with the entire population $(7 \%){ }^{14}$

It is interesting how, besides a shared experience of feeling better prepared for each stage of the COVID-19 situation, the development from the first to the second COVID-19 wave was experienced differently by the leaders, when they were divided into different management levels. Ward managers more often experienced being able to work in a way consistent with their own beliefs and values. This could be explained by the initiatives, focusing on the role of ward managers, which followed as a result of Survey I.

When comparing Survey I to Survey II, more ward managers experienced feeling overloaded and more concerned about their own health in Survey II. This may be explained by the constant pressure experienced by the leaders. ${ }^{3}$ Firstly, in the first wave, then in between the waves, where they had to catch up with the many postponed treatments, and now a new wave ahead of them without knowing, how long it would last, and if it would be the last one. Being under constant pressure, with no visible deadline, may be helped by a relationship-oriented leadership model that focuses on leaders being authentically other-centred for the benefit of collaboration and more able to adopt an "I-Thou" relationship with associates. $^{15}$

The leaders, who were head of department, experienced significant development in relation to a better overview and being well prepared, dealing with more meaningful tasks and having influence on discussion as well as being better informed. Even though initiatives focusing on the role of ward managers were prioritised and implemented because of the first COVID-19 wave, heads of departments experienced a more positive development from the first to the second COVID-19 wave. This may be because the initiatives to meet ward managers needs are new. They have reached the higher management level and not yet broken through to ward managers.

Despite the organizations' intention to support all leaders during the COVID-19 pandemic, the differences in the leaders' experiences, depending on management level, are concerning, and it is clear that it is the heads of departments that benefit and develop most during crisis.

The experiences of the leaders with formal management education developed in both positive and negative directions, as they, on the one hand felt better prepared and had more influence, but on the other hand were more worried about their own health. The reason for this is difficult to explain, but one suggestion could be that due to their educational competencies, they were capable of transforming the new situation in a constructive manner, and at the same time, reflecting more on the personal consequences. $^{16}$ This finding supports that a learning 
culture for practice development may be developed through continuous education of leaders.

The limited changes among leaders without formal management education underlines the need to be extra attentive towards strengthening their competencies, and to focus on conducting a relationship-oriented leadership. ${ }^{15}$ These leaders may be in a situation, where their experience of lacking support from their employees may result in them leaving their leadership positions despite having uncovered potentials. This is consistent with a review of nursing leadership, which found that lack of management training and education focusing on clinical leadership was a barrier for leadership development. $^{17}$

To the group, who had more than five years of experience, a positive pattern was seen, as they more often felt prepared, had influence on the decisions made and felt more informed by their nearest leader. This may be explained by them being more experienced as leaders, and thus a greater probability of having a management education providing them with more comprehensive knowledge. ${ }^{8}$ Further, their longer length of experience makes them more confident in the role as leader, they know where to seek information, and who to turn to when having questions or in need of support. This finding is consistent with evidence that demonstrates the importance of length of experience matched with relevant management education. ${ }^{18}$ As has been demonstrated in studies of nursing expertise, years of experience are not enough to develop expertise and effectiveness. ${ }^{19}$

\section{Study Limitations}

The main limitation of our study is that we were only able to compare participants, who completed both surveys. Both surveys had a high individual response rate (Survey I $72 \%$ and Survey II $80 \%$ ), but only 89 managers answered both surveys. The choice of analysis also resulted in only a small number of leaders with 0-2 years of experience participating in both surveys. This limited the extent of the analysis from this group, as it was not a valid population size. ${ }^{11}$

\section{Conclusion}

This study presents the comparative analysis of two leadership surveys conducted during two waves of the COVID-19 pandemic in Denmark. The findings highlight important leadership development issues that need to be considered in the time after the pandemic. This may include considerations regarding management level, formal management education and years of experience as a leader. It is clear from our findings that preparedness for crisis is a key consideration, and one that requires strategic leaders to consider how leadership practices may be transformed and even better prepared in the future.

\section{Data Sharing Statement}

Anonymized data can be obtained by contacting the authors.

\section{Ethics Approval and Informed Consent}

Permission to conduct the study was received from the hospital management and the Danish Data Protection Agency (REG-026-2020) and The National Committee on Health Research Ethics approved the study (J.nr. 20000013). This study was conducted in accordance with the principles of the Declaration of Helsinki. ${ }^{20}$ Informed consent was obtained from each participant at the opening page of the online questionnaire.

\section{Author Contributions}

All authors made a significant contribution to the work reported, whether that is in the conception, study design, execution, acquisition of data, analysis and interpretation, or in all these areas; took part in drafting, revising or critically reviewing the article; gave final approval of the version to be published; have agreed on the journal to which the article has been submitted; and agree to be accountable for all aspects of the work.

\section{Funding}

There were no external sources of funding.

\section{Disclosure}

The authors report no conflicts of interest in this work.

\section{References}

1. Greenberg N, Tracy D. What healthcare leaders need to do to protect the psychological well-being of frontline staff in the COVID-19 pandemic. BMJ Lead. 2020;leader-2020-000273. doi:10.1136/leader2020-000273

2. Dinibutun SR. Factors associated with burnout among physicians: an evaluation during a period of COVID-19 pandemic. J Healthc Leadersh. 2020;12:85-94. doi:10.2147/JHL.S270440

3. Hølge-Hazelton B, Kjerholt M, Rosted E, Hansen ST, Borre LZ, McCormack B. Improving person-centred leadership: a Qualitative Study of ward managers experiences during the COVID-19 crisis. Risk Manag Healthc Policy. 2021;14:1401-1411. doi:10.2147/RMHP. S300648 
4. McCormack B, Dewing J, Breslin L, et al. Practice development: realising active learning for sustainable change. Contemp Nurse. 2014;32(1-2):92-104. doi:10.5172/conu.32.1-2.92

5. Polit DF, Beck CT. Nursing Research: Generating and Assessing Evidence for Nursing Practice. 10th ed. Wolthers Kluwer; 2017.

6. Thorne S. Toward methodological emancipation in applied health research. Qual Health Res. 2011;21(4):443-453. doi:10.1177/ 1049732310392595

7. Elm E, Altman DG, Egger M, Pocock SJ, Gøtzsche PC, Vandenbroucke JP. Strengthening the reporting of observational studies in epidemiology (STROBE) statement: guidelines for reporting observational studies. BMJ. 2007;335(7624):806-808. doi:10.1136/ bmj.39335.541782.AD

8. Hølge-Hazelton B, Kjerholt M, Rosted E, Hansen ST, Borre LZ, McCormack B. Health professional frontline leaders' experiences during the COVID-19 pandemic: a Cross-Sectional Study. $J$ Healthc Leadersh. 2020;2021(13):7-18. doi:10.2147/JHL.S287243

9. Jenn NC. Designing a questionnaire. Malays Fam Physician. 2006;1 (1):32-35.

10. SurveyXact by Ramboll; 2018. Available from: https://www.surveyx act.com/. Accessed November 10, 2017.

11. Verma JP, Abdel-Salam ASG. Testing Statistical Assumptions in Research. John Wiley \& Sons; 2019.

12. Møller Petersen K. Smittetryk og samfundssind - kritiske nedslag $i$ coronaens tid [Infection Pressure and Societal Mind - Critical Impacts in the Time of the Corona]. 1st ed. University of Southern Denmark Studies in History and Social Sciences; 2020.
13. John Hopkins University \& Medicine. COVID-19 map. Johns Hopkins Coronavirus Resource Center. Available from: https:/coro navirus.jhu.edu/map.html. Accessed May 31, 2021.

14. SSI. Prævalensundersøgelse af covid-19 [Prevalence study of covid19]. March 1, 2021. Available from: https://covid19.ssi.dk/overvag ningsdata/undersoegelser/praevalensundersogelsen. Accessed May 6, 2021.

15. Cardiff S, McCormack B, McCance T. Person-centred leadership: a relational approach to leadership derived through action research. J Clin Nurs. 2018;27(15-16):3056-3069. doi:10.1111/jocn.14492

16. Cole M. Learning through reflective practice: a professional approach to effective continuing professional development among healthcare professionals. Res Post Compuls Educ. 2000;5(1):23-38. doi:10.1080/13596740000200067

17. Hughes V. What are the barriers to effective nurse leadership? A review. Athens J Health. 2018;5(1):7-20. doi:10.30958/ajh.5-1-1

18. Amagoh F. Leadership development and leadership effectiveness. Manag Decis. 2009;47(6):989-999. doi:10.1108/0025174091 0966695

19. Brenner P, Tanner C, Chesla C. Expertise in Nursing Practice. 2nd ed. Springer Publishing Company; 2009.

20. WMA Declaration of Helsinki. Ethical principles for medical research involving human subjects; 2020:4. Available from: https:// www.wma.net/policies-post/wma-declaration-of-helsinki-ethical-prin ciples-for-medical-research-involving-human-subjects/. Accessed April 11, 2020.
Journal of Healthcare Leadership

\section{Publish your work in this journal}

The Journal of Healthcare Leadership is an international, peer-reviewed, open access journal focusing on leadership for the health profession. The journal is committed to the rapid publication of research focusing on but not limited to: Healthcare policy and law; Theoretical and practical aspects healthcare delivery; Interactions between healthcare and society and evidence-based practices; Interdisciplinary decision-making;

\section{Dovepress}

Philosophical and ethical issues; Hazard management; Research and opinion for health leadership; Leadership assessment. The manuscript management system is completely online and includes a very quick and fair peer-review system. Visit http://www.dovepress.com/ testimonials.php to read real quotes from published authors. 